


\title{
TELLO Y LA ARQUEOLOGIA DE LA CEJA DE SELVA
}

\author{
Duccio Bonavia \\ Universidad Cayetano Heredia - Lima
}

La arqueologia de la ceja de selva y de la selva baja han sido, y siguen siendo, terrenos virgenes y fértiles para esta ciencia. La selva como región natural es una área muy extensa, sobre la que nuestros conocimientos se reducen a trabajos aislados y a intentos pioneros. Sin embargo, se trata de un área con un potencial tal, que no sólo nos deparará grandes sorpresas en el futuro, sino que encierra las soluciones a muchas preguntas que se han planteado los estudiosos de la Cultura Andina, y sin las cuales será imposible el cabal entendimiento de nuestro desarrollo cultural.

Son tan escasos los trabajos realizados en esta región, que intentar un recuento no es cosa difícil.

No cabe duda que la arqueología científica en el Oriente peruano comienza solamente en 1900. Sin embargo hay algunos trabajos precursores, de viajeros ilustrados del siglo XIX que no podemos dejar de mencionar y cuyos aportes, a pesar de todo, son imprescindibles si se quiere abordar el problema con conocimiento de causa.

Poco divulgadas son las descripciones que hacen de Choquequirao, en la cuenca del Apurímac, el Vizconde Eugene de Sartiges (1850) y Léonce Angrand (1858). Sin embargo pese a que José Toribio Polo (1905) y Manuel González de la Rosa (1908) se ocupan de él y Bingham publicó un artículo corto en 1911, dicho conjunto espera aún ser estudiado cientificamente.

No es el caso mencionar detalladamente la contribución de Antonio Raimondi (1942) en cuyas Notas de Viaje hay valiosa información para el arqueólogo. El recorre más de una vez entre 1855 y 1864 la ceja de selva, la selva, y señala buena cantidad de restos arqueológicos. Recordaremos sólo las del área del Marañón (Castillo de Chupan), la descripción de Ollantaitambo en el Urubamba y los conjuntos del valle del Utcubamba.

Charles Wiener (1880), viajero duramente criticado por algunos de sus dibujos fantasiosos y la inexactitud de algunas de sus descripciones, merece ser leído con mayor cuidado. Es quien menciona por primera vez la existencia de Machu Picchu y Huayna Picchu, y aun cuando no logra visitarlos, los ubica en forma exacta en su mapa del Valle de Santa Ana. Uno de los pocos que 
reivindica al estudioso francés en este sentido, es Raúl Porras Barrenechea en sus Fuentes Históricas Peruanas (1955).

A principios de 1900, visita el Perú Adolph Alphonse Bandelier (1907) y deja buenas notas sobre el área de Chachapoyas, especialmente sobre las ruinas de Cuelap, descubiertas por el prefecto Nieto en 1850. Investigaciones sobre el mismo sitio hicieron antes y después Raimondi (1859), Werthemann (1892), Kieffer (1910), Langlois (1935-1936) y Hans Horkheimer (1959), a quien debemos un trabajo de síntesis sobre la arqueología del valle del Utucubamba. Sin embargo, pese al tiem po transcurrido, el trabajo de Langlois sigue siendo uno de los más completos realizados sobre dicho monumento y el área en general.

La segunda década del siglo XX está estrechamente vinculada a uno de los descubrimientos más sensacionales de la arqueología y cuyos ecos, a pesar del tiem po transcurrido, se mantienen. Nos referimos a las investigaciones de Hiram Bingham y al descubrimiento científico de Vilcabamba y Machu Picchu (1930). Este altimo, nombre mágico convertido ya en mito, magnificado por historiadores, poetas y artistas y cuyos restos están hoy condenados a un triste destino por la incuria del Estado, la ineficiencia de algunos arqueólogos y la lacra del turismo masivo.

La investigación de Hiram Bingham es la primera de cierta envergadura que tiene como finalidad el estudio de grupos arqueológicos en la ceja de selva. Si en muchos aspectos la parte científica deja mucho que desear, ésta nos reveló no sólo el conjunto de Machu Picchu, sino una serie de otras estaciones arqueológicas, y sobre todo abrió la posibilidad e incentivó otras investigaciones que se llevaron a cabo en el área años más tarde.

Hacia 1940 inicia sus investigaciones en el valle del Urubamba, Paul Fejos. Lo hace en forma menos espectacular que Bingham y, hasta cierto punto, sus trabajos pasan desapercibidos, como la mayoría de trabajos científicos. Pero el aporte de Fejos, con su libro Archaeological explorations in the Cordillera Vilcambamba, Southeastern Peru (1944), marca uno de los hitos más importantes de la arqueología de la ceja de selva. Recorre el área, estudia algunos de los yacimientos señalados por Bingham, descubre otros y deja una información mucho más valiosa que la de aquél. Uno de los arqueólogos que excava entonces con el equipo de Fejos es John Howland Rowe (1944). Su nombre es indesligable de la arqueología cuzqueña, pero sus excavaciones en Sayac Marca y Choqueysusuy son poco conocidas.

A partir de 1946 se ocupan de la arqueología de la ceja de selva Henri Reichlen (1950), quien recorre el área Chacha; Donald Thompson (1969) que estudia en el área de Huánuco y con Roger Ravines (1973) baja al Marañon; William Isbell (1968) en la cuenca del Inambari, mientras el autor de estas notas explora el área del Mantaro $(1968 \mathrm{a}, 1970,1972)$ y excava en Yaro (mal 
conocido como Pajatén, 1968b).

Pero sin duda alguna el mayor logro en la arqueologfa del área oriental se debe a Donald Lathrap. Sús esfuerzos están dirigidos a estudiar la selva baja. Con él se inicia toda una escuela que tuviera sus antecedentes en los trabajos de Harry Tschopik y son muchos los alumnos de Lathrap que han dejado ya aportes sustantivos. La síntesis de las investigaciones de Lathrap están condensadas en The Upper Amazon (1970), uno de los textos más importantes que se han publicado en los últimos años sobre la arqueologfa andina. Además, es quien ha aportado una serie de ideas y datos concretos que avalan hasta cierto punto algunos planteamientos de Tello y sin los cuales las ideas del arqueólogo peruano hoy no tendrfan mucho sentido.

No puede dejarse de mencionar las investigaciones de Erland Nordenskiöld y Stig Rydén en el área oriental boliviana, cuyos aportes son fundamentales para la comprensión del área selvatica peruana.

Podría parecer ocioso haber tratado de sintetizar la historia de las investigaciones arqueológicas en la ceja de selva y la selva del Perú, para referirse concretamente a la obra de Tello y sus planteamientos sobre el oriente peruano; creemos, sin embargo, que si no se sitúan estos hechos dentro del contexto histórico en el que se dieron, sería un tanto difícil darles su justo valor; y todo aporte que se señale o critica que se haga, no podrían ser juzgados a cabalidad.

En realidad Tello, quien trabajó a lo largo y ancho del territorio nacional, investigó poco en la zona selvatica. $Y$ esto es evidentemente una profunda contradicción de su vida, si se considera el planteamiento teórico medular de su hipótesis sobre el origen oriental de la Civilización Andina. Pero no hay que olvidar que Tello, como muchos grandes precursores, fue un hombre intuitivo y muchas de sus afirmaciones, si se analizan cuidadosamente, son en última instancia fruto de estas intuiciones. En el caso de la selva, éstas se basan en su conocimiento de la mitología amazónica, el estudio de los idiomas y de la etnografía de las tribus de la selva. La base de la inferencia de Tello, para afirmar que el origen de la cultura peruana estaba en la selva y no en la costa, se sustentan casualmente en estos estudios lingüísticos, considerando la presencia de su substrato básico. Caribe- Arawak -Tupi, en toda el área andina. Su análisis de los mitos selváticos, como el de la mujer devorada por el tigre, del muchacho que construye una liana para subir al cielo, más las referencias históricas proporcionadas por los misioneros, como los padres Pío Aza o Sobreviela, tuvieron más influencia en él, que las referencias materiales. Pues, evidentemente, las únicas ilustraciones que Tello tuvo a la vista sobre cerámica antigua de la selva, fueron las de Tessmann (1930).

En efecto, y pese a que hoy muchos hechos le están dando la razón, cuando Tello irrumpe en la escena de la arqueología peruana para defender los 
orígenes andinos, lo hace fundamentalmente para oponerse a las ideas de Uhle y Larco Hoyle que querían explicar el fenómeno como consecuencia de otras culturas extrañas a las nuestras, dándole mayor originalidad al área costeña. Surge asi, en contraposición, su teoría del origen selvático. Tello hizo bandera de estos planteamientos, pero como escribiera algu na vez Kroeber que lo conoció y admiró, fueron resultado de una "apasionada convicción, más que como el fruto de una evidencia cientiffica" (Porras, 1955: 85).

En efecto, Tello realiza trabajos en la ceja de selva sólo en dos oportunidades: en 1937 cuando organiza la expedición al Marañón, y en 1941 cuando investiga en el área del Urubamba. Respecto a la primera ha quedado alguna información (1937), especialmente sobre la zona de Balsas y Chachapoyas. Sin embargo, de sus actividades en el Urubamba to mejor de sus investigaciones ha quedado inédito. Lo poco que conocemos, es información de segunda mano, consignada en la tesis de Bachiller de Manuel Chávez-Ballón y en el libro de Porras (op. cit.). Este último erróneamente le atribuye el descubrimiento de Huiñay Huayna (1955, p. 83); loevidente es que la ciudadela se descubrió durante los trabajos de la Expedición Científica Wenner-Gren a la América Hispánica y Tello lo único que hizo fue darie nombre.

En su libro Origen y Desarrollo de las Civilizaciones Prehistóricas Andinas (1942), Tello dedica un capítulo, el V, a la "A rqueología del Anti Suyo". Es en estas páginas donde se encuentra condensada la información que sobre esta parte del territorio tenía el arqueólogo peruano y cuáles eran sus ideas al respecto.

En dos oportunidades (pp. 45 y 46) señala acertadamente no sólo el hecho que se trata de una de las áreas menos conocidas, sino que remarca la necesidad de que ésta sea estudiada. Sus aseveraciones siguen vigentes.

Hay algo, sin embargo, en estas páginas que llama la atención. Me refiero a las "áreas de importancia" arqueológica que señala y que se refieren concretamente al sur y al centro, olvidando el área del norte, que hoy sabemos reviste tanta importancia como las otras. Esto no tiene una explicación, desde que ya en la época de Tello los monumentos del área de Chachapoyas eran perfectamente conocidos, e inclusive él los había visitado.

En este sentido uno de los aportes teóricos más importantes de Tello es el haber comprendido la magnitud del papel que ha jugado el Oriente peruano en la domesticación y difusión de plantas, lo que se ha convertido en uno de los fenómenos más saltantes de la cultura americana indígena. Esto es más relevante, si se tiene en cuenta que consideraciones de esta naturaleza, eran un tanto ajenas al quehacer arqueológico de la época y fueron preocupación solo por parte de una pequeño grupo de visionarios.

Tello es uno de ellos y señala en su libro una lista de plantas que tuvieron origen amazónico. Dicha nómina, en términos generales, está bien formulada si 
excluímos el algodón y el maíz, que evidentemente provienen de otra ecología.

La referencia a los caminios incaicos de penetración a la ceja de selva y selva baja, es otro de los aportes importantes de Tello que no han sido tomados en cuenta (p. 42). Tello se refiere fundamentalmente a caminos de tres áreas geográficas: de Chachapoyas, del Huallaga y de la zona del Cuzco. Evidentemente sobre este aspecto es poco lo que se ha adelantado y los autores que, después de Tello, han investigado sobre la materia, poco o nada han aportado. Sẻ señalan siempre los grandes caminos incaicos longitudinales con sus ramales transversales en costa y sierra, pero nada se dice sobre la gran red de caminos de penetración que existía, y que fueron la base que permitió la colonización de la ceja de selva por los incas. En este sentido los caminos incaicos cumplieron la misma función que los caminos romanos y se extendieron hasta los mismos limes del Imperio.

Quienes hemos trabajado en la ceja de selva, no sólo hemos podido comprobar este fenómeno, sino que nos ha llenado de asombro encontrar largos tramos empedrados y con escalinatas que facilitaban el tránsito en áreas de topografía muy difícil, entre la vegetación exuberante, y en aquellos lugares en que los senderos actuales utilizados por los arrieros, dan largos rodeos para evitar justamente esos puntos difíciles.

Una de las preocupaciones fundamentales de Tello, fue establecer los rasgos culturales que tipifican cada una de las tres regiones naturales del territorio andino. Este tema es tratado con cierta amplitud (pp. 43-46), aunque los argumentos -si excluímos el de la botánica- no tienen la solidez necesaria, y posiblemente Tello no meditó suficientemente sobre ellos, pues hubiera podido fácilmente encontrar elementos de juicio más apropiados.

No cabe ninguna duda sobre el origen selvático de los queros incaicos, sobre lo que insiste enfáticamente Tello. Lo que no se llega a entender es el planteamiento del autor para tratar de establecer el mismo tipo de vinculaciones, pero en este caso entre la selva y la costa del Perú, para lo que él denomina "Cultura Chanka" y que no es otra cosa que una fase terminal del estilo Nasca. Las evidencias que se presentan son vagas y se nota perfectamente que se fuerza el argumento dir íase, casi sin convicción.

Otro argumento que utiliza es el de las cabezas-trofeo, que aparecen con cierta frecuencia en la zona costeña. Pero si bien nadie puede negar que efectivamente es un fenómeno vinculado a la selva, no podemos considerarlo directo. Hoy sabemos que las relaciones con la selva son muy antiguas, se remontan a la Epoca Precerámica. Se trata, pues, de rasgos que se han difundido lentamente a lo largo de miles de años y que, cuando los encontramos en épocas tardfas, forman parte de patrones culturales muy bien establecidos y que han asimilado valores que originalmente no les pertenecían. 
Mucha importancia le atribuye Tello a las hachas de piedra y no sólo considera que es un fenómeno típicamente amazónico, sino que afirma (pp. 4446) que la difusión se ha dado en un solo sentido, de este a oeste. En primer lugar se hace muy difícil la generalización, en cuanto no hay un solo tipo de hachas en la selva y no todos éstos pertenecen al mismo fenómeno cultural ni a la misma época. Hay una larga tradición de hachas pulidas de piedra en el Area Andina, que se remonta al Precerámico en la costa extremo Norte, en la selva aparece en las fases tempranas del estilo Tutischainyo, y es muy común en las épocas tardías en los antiguos campos de cultivo de la ceja de selva. De modo que su difusión, en concordancia con los datos hasta ahora disponibles, resulta contraria a la señalada por Tello.

Muy acertado es Tello cuando trata de describir los patrones de establecimiento de la ceja de selva, así como su situación ecológica. En efecto, las construcciones "... ubicadas en hileras casi continuas sobre las colinas y faldas elevadas de los cerros que encierran aquellas quebradas y valles de la montaña" (p. 44) corresponden perfectamente a los patrones de ocupación de la ceja de selva. Es exactamente idéntico al que estudiamos en el área del Mantaro y que se puede extender a toda el área central. Lo que le faltó a Tello fue comparar dicho patrón con los del norte y el sur. Sólo así hubiera notado el cambio y se hubiera dado cuenta de que no se puede hacer generalizaciones.

En la página 45 de su citado libro hay unas líneas que, a nuestro juicio, revisten gran importancia, si es que se quiere conocer bien las razones por las que estas poblaciones existieron en una zona tan inhóspita, como es la ceja de selva. Al referirse a las poblaciones, acota: “. . éstas son tanto más numerosas y grandes cuanto más cercanas se hallan de las grandes fuentes agrícolas o de los productos naturales valiosos". En efecto así es, y lo hemos venido sosteniendo con Ravines desde hace muchos años (1967); el proceso que se dió durante el incario no fue casual, ocasional, ni individual. Fue un fenómeno dirigido, de colonización de la ceja de selva por parte del Estado Inca, con la finalidad fundamental de tener acceso a una serie de productos naturales que no podian obtenerse en el área serrana, al mismo tiempo que se cultivaban aquellos productos llevados del Ande por el hombre y que podían adaptarse a esa nueva ecología, como es el caso del maíz. No se trató, pues, como se sostuvo durante mucho tiempo, de núcleos enclavados en zonas difíciles de la ceja de selva a manera de avanzadas militares de defensa, sino de colonos que iban a cultivar y cuya existencia dependía directamente de la metrópoli.

Por otra parte, el viejo conocimiento de la etnociencia indígena llevó a Tello a entrever, aunque no a explicar, la existencia de un patrón andino de complementariedad y aprovechamiento de los diversos pisos naturales. En efecto, cuando se refiere a los poblados esparcidos en la ceja de selva, escribió: 
"...tuvieron a la mano tanto los productos de la montaña como los de las regiones altas. .." (p. 45).

Es demasiado conocido ya, y no merece la pena insistir, sobre el hallazgo que hizo Tello en 1935 de las ruinas de Kotosh, cerca de Huánuco, y que adquirieron importancia por los trabajos de la Expedición Científica a los Andes de la Universidad de Tokyo.

Intenta Tello hacer una lista de las ruinas de la ceja de selva (p. 45) pero se limita al área del Cuzco y a la limítrofe boliviana. Por razones que desconocemos, no incluye ninguno de los núcleos importantes del Urubamba que ya se conocían entonces, ni otras estaciones de la zona norte, que luego menciona en forma incidental (p. 46) en otro lugar. Por otro lado, Tello no tuvo la oportunidad de visitar la mayoría de estos sitios. Conoció algunos, recibió noticias de los otros. Este fue uno de los defectos más graves de Tello; hacía suyas las informaciones que recibía, y sólo en contadas ocasiones citaba, la fuente. De allí que se haya atribuído descubrimientos que nunca hizo.

A lo largo de toda su exposición menciona más de una vez los movimientos migratorios de este a oeste y viceversa, pero se nota claramente que no hay una conciencia clara de la forma en que se dieron estos movimientos y en qué momento fueron más acentuados. Deja entrever que está pensando nó sólo en movimientos de elementos culturales, sino también en movimientos de poblaciones, lo que - hasta donde sepamos- de este a oeste no se dio. Además, pese a muchas incógnitas, sabemos que desde épocas muy tem pranas hubo contactos. pero que al principio fueron movimientos de grupos muy pequeños y que se efectuaban en forma totalmente independiente. Este proceso se fue organizando, hasta que al producirse el fenómeno incaico, se convierte en una colonización dirigida, con normas bien establecidas y estrictame it $_{\mathrm{i}}$ control adas por el estado. Fue un proceso tan dependiente de la metrópoli, que cuando se produce el colapso del Imperio Incaico, las colonias fueron abandosadas y pronto cubiertas por la maraña de la selva.

Tello, evidentemente, no pudo darse cuenta de todo este largo proceso; no tenía a su alcance los conocimientos necesarios para ello. Nota sin embargo, que este movimiento, en su fase final, está estrechamente ligado a la organización incaica. En efecto, si bien él no lo señala en el texto, lo está indicando en su cuadro de Edades de la Civilización Andina.

Es más, hay algo que no se puede entender claramente en el texto de Tello, pero que deja abierta una interesante posibilidad. Nos referimos concretamente al mapa de la lámina VI, donde se ilustran Las Culturas de la Cuarta Edad, que corresponden a lo que Tello llamaba "La Civilización del Tawantinsuyo". En dicho mapa, las naciones del Anti Suyo, o sea las correspondientes a la ceja de selva, están divididas en dos sub-áreas. ¿Quiso con esto señalar que hubo dos 
tradiciones direrentes en dicha área? Al decir de Toribio Mejía Xesspe, uno de los colaboradores de Tello, así es. Desafortunadamente nada ha quedado escrito. A nosotros nos parece importante, en cuanto hemos planteado (1972) que en el área de ceja de selva hubo no dos, sino tres tradiciones diferentes, que se reflejan en sus patrones de establecimiento y en su arquitectura. Sería interesante conocer las notas de Tello al respecto,para saber cuáles fueron los fundamentos que lo llevaron a efectuar esta división, en una época en la que habla aún muy pocas evidencias.

Tello en este sentido es evidentemente un precursor. Si se juzgan sus escritos a la luz de los conocimientos de su época, ello se hace mucho más patente. El le otorga importancia a la ceja de selva, cuando casi nadie lo hacía. Es más, esta enseñanza no fue utilizada ni comprendida; al extremo que hasta hace muy poco tiempo se siguió escribiendo, que la ceja de selva fue un obstáculo no superado por la Civilización Andina. $Y$ esto no es cierto. Ignorarlo es desconocer uno de los logros más importantes del hombre andino, pues se trató de conquistar y de domesticar uno de los medios más difíciles y hostiles del territorio, y que aún hoy permanece como un reto. Sin esta gran conquista, la historia de la Cultura Andina no tendría ningún sentido, pues sólo con el dominio de la ceja de selva, y a través de ella de sectores de la selva baja, los lfmites del Tawantinsuyo alcanzaron verdaderamente las "cuatro partes del mundo".

\section{BIBLIOGRAFIA}

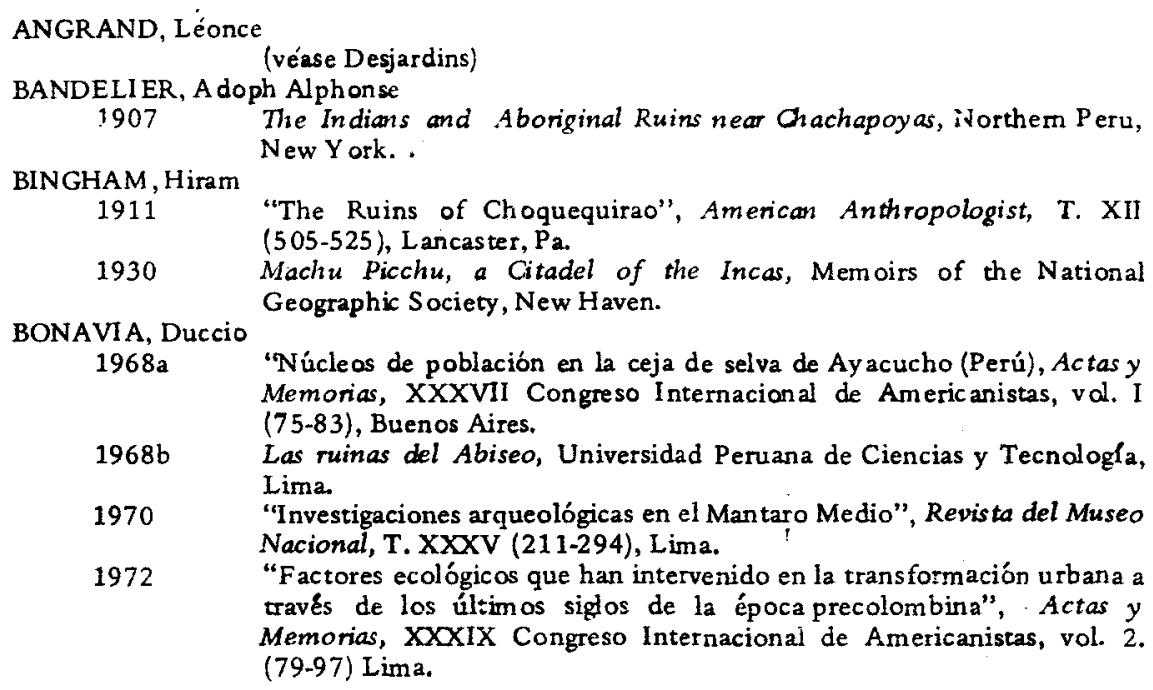


BONAVIA, Duccio y Rogger Ravines

1967 "Las fronteras ecológicas de la civilización andina", Amaru, No2, (61-99), Lima.

DESJARDINS, Ernst

1858 Le Pérou avant la conquéte espagnole d'aprés les principaux historiens originaux et quelques documents inédits sur les antiquités de cet pays Parls (pp. 127 ss.)

FEJOS, Paul

1944 Archaeological explorations in the Cordillera Vilcabamba, Viking Fund Publications in Anthropology, No 3, New York.

GONZALEZ DE LA ROSA, Manuel

1908 "A propos de la redécouvert de la ville antique de Choquequirao sur la rive droite de l'Apurimac, (Pérou), Joumal de la Société des América-

HOR KHEIMER, Hans nistes, T. V, No 2 (5-8), Paris.

1959

"Algunas consideraciones acerca de la arqueología en el valle del Utcubamba", Actas y trabajos del II Congreso Nacional de Historia del Perú, Vol. I, (71-90) Lima.

ISBELL, William $\mathrm{H}$.

1968 "New discoveries in the Montaña southeastern Peru", Archaeology, Vol. 21, No 2, (108-114), Brattleboro.

KIEFFER, Philippe

1910 "Excursión a Cuelap", Revista Universitaria, Año V, Sem. II, (145-162) Lima.

LANGLOIS, Luis

1935

"Las ruinas de Cuelap", Bole tín de la Sociedad Seográfica de Lima. T. LI, (20-34), Lima.

1936 Utcubamba, Investigaciones arqueolbgicas en este valle del Dpto. de Amazonas (Perú)", Revista del Museo Nacional, Año VIII, No 2 (224-249); Año IX, No 1, (33-72); Año IX, No 2 (191-228) (1939 y 1940), Lima.

LATHR AP, Donald W.

1970 The Upper Amaron, Thames and Hudson, Londres.

POLO, José Toribio

1905 "Informe al Instituto Histórico del Perú sobre las ruinas de Choquequirao", Revista Histórica, No 2 s/p, Lima.

PORRAS BARRENECHEA, Raúl

1955 Fuentes Históricas Peruanas, Juan Mejía Baca \& P.L. Villanueva Editores. Lima.

RAIMONDI, Antonio

(1942-1943) Notas de viajes para su obra "El Peri", Imprenta Torres Aguirre, Vol. . 1 y 2 , Lima.

REICHLEN, Henri et Paule

1950 "Récherches archéologiques dans les Andes du Haut Utcubamba", Joumal de la Société des Américanistes, T. XXXIX, (210-246) Paris.

ROWE, John $\mathrm{H}$. 1944

TELLO, Julio César

"Report by ... on excavations at Choquesuy suy", Archeological explorations in the Cordillera Vilcabamba, Southeastem Peru, Viking Fund Publications in Anthropology, $N \circ 3,(63-65)$ New York.

1937 "Objetoy propósito de la Expedición Arqueológica al Marañón", El Comercio, (31 de octubre) Lima.

1942 Origen y desarrollo de las Civilizaciones Prehistóricas Andinas, Lima.

SARTIGES, Eugene (bajo el seudónimo de E. de Lavandais)

1850 "Choquequirau", Revue des Deux Mondes, (T.X: 1019 y siguientes), Paris. 
TESSMANN, Günter

1930

Die Indianer Nordost - Perus. Hamburg.

THOMPSON, Donald

1969

"Incaic installations at Huanuco and Pumpu", El proceso de urbanización en América desde sus origenes hasta nuestros dlas. Editorial del Instituto, (67-74), Buenos Aires.

THOMPSON, Donald; RAVINES, Rogger

1973

"Tinyash, a prehispanic village in the Andean Puna", Archaeology, Vol.

WERTHEMANN, Arthur 26, N०2,(94-100), Blattleboro.

1892

WIENER, Charles

1880
"Ruinas de la fortaleza de Cuelap", Boletín de la Sociedad Geográfica, de Lima, T. II (148-153), Lima.

Perou et Bolivie. Récit de voyage suive d'etudes archeologiques et ethnographiques et des notes sur l'ecriture et les langues des populations indiennes. Paris. 